\title{
The screening of visual impairment among preschool children in an urban population in Malaysia; the Kuching pediatric eye study: a cross sectional study
}

\author{
Mallika Premsenthil ${ }^{1}$, Rose Manju², Asokumaran Thanaraj ${ }^{3}$, Syed Alwi Syed Abdul Rahman ${ }^{4}$ and Tan Aik Kah*
}

\begin{abstract}
Background: To screen for visual impairment in Malaysian preschool children.

Methods: Visual screening was conducted in 400 preschool children aged 4 to 6 years. The screening involved two basic procedures; the distant visual acuity test using the Sheridan Gardiner chart and the depth perception test using the Langs stereoacuity test. Criteria for referral were a visual acuity of 6/12 or less in the better eye or a fail in the depth perception test.

Results: The prevalence of visual impairment was $5 \%$ ( $95 \%$ confidence interval $[\mathrm{Cl}]=3.3,7.6)$. Of the 400 preschool children screened, 20 of them failed the distant visual acuity test or the stereopsis test. Refractive errors were the most common cause of visual impairment $(95 \%, 95 \% \mathrm{Cl}=76.2,98.8)$; myopic astigmatism was the commonest type of refractive error $(63.2 \%, 95 \% \mathrm{Cl}=40.8,80.9)$.

Conclusion: The study is a small but important step in the effort to understand the problem of visual impairment among our preschool children. Our study showed that it is feasible to measure distant visual acuity and stereopsis in this age group.
\end{abstract}

Keywords: Preschool children, Eye screening, Prevalence, Visual impairment, Distant visual acuity, Stereopsis, Amblyopia

\section{Background}

Vision is an important requirement for learning and plays a critical role in the development of a child during the first three years of life. Children use their sight to strengthen motor functions, establish parent-child bonding, build picture perception and gain their balance [1]. Children may enter school with vision problems. Sub-optimal vision could lead to poor school performance, lack of interest in schooling, and dropping out of school. Sometimes an underlying vision problem can manifest as behavioral problems like learning disabilities, dyslexia and attention deficit disorder [2]. The common

\footnotetext{
* Correspondence: portwinestain@hotmail.com

'Department of Ophthalmology, Faculty of Medicine and Health Sciences, Universiti Malaysia Sarawak (UNIMAS), Lot 77, Seksyen 22, Kuching Town Land District, Jalan Tun Ahmad Zaidi Adruce, Kuching, Sarawak 93150, Malaysia

Full list of author information is available at the end of the article
}

eye problems that can occur in children of preschool and early school age include amblyopia, strabismus and refractive errors [3]. Early detection provides the best opportunity for effective treatment. The American Academy of Pediatrics recommends early vision screening at 3 years of age [4].

Amblyopia affects $5 \%$ of the preschool children and is potentially treatable [5]. The two common causes of amblyopia are strabismus and refractive errors. Early detection is critical because it increases the likelihood of successful treatment. Preschool screening programs may result in better visual outcome than screening at school entry. In Malaysia, the nationwide eye screening program effectively covers only primary school children who are 7 years of age and above, but does not include children in the preschool age ( 6 years and below). To date, there is no data on the prevalence of vision problems among

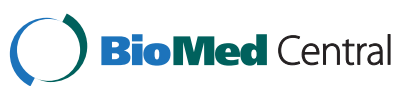


preschool children in Borneo Island. In this report, we provide information on the magnitude and type of visual problems. This data will aid in the estimation of the need for an eye screening program among preschool children in our population.

\section{Methods}

The Kuching Pediatric Eye Study research protocol was approved by the University Malaysia Sarawak (UNIMAS) Human Subjects Ethics committee [Project ID: SGS/01 (S63)/761/2010(38)]. The study was conducted in accordance with the Helsinki's declaration and written informed consent obtained from parents of all participants.

\section{Design and sample}

The Kuching Pediatric Eye Study was a cross-sectional study involving 400 preschool children, aged 4 to 6 years in Kuching district, Malaysia. Data was collected from the year 2010 to 2011. Kuching has a population of 617,887 . About $8.34 \%(51,530)$ are preschool children [6]. The list of kindergartens in Kuching district was obtained from the Sarawak State Education Council. The number of kindergarten in Kuching district included 122 government and 89 private preschools. Preschool children were selected by simple random sampling. Numbers were randomly assigned to all the preschools and the screening population was selected by SPSS random selection methods. Sample size was calculated for an expected prevalence rate of $20.6 \%$ and for a precision of $4.0 \%$.

\section{Site inspection and informed consent}

After identification of the kindergartens, the respective principals were approached and informed about the study. Upon agreement, the schools were inspected for the suitability of the screening process. A school is considered suitable if there is a room with more than 4 meter long which is free from distractions. The light level should be adequate (at least 300 lux in the room and test chart illumination of about 500 lux). Consent forms, questionnaires and information sheets were distributed to the parents two weeks before the screening procedure. The consent forms, questionnaires and information sheets were written in three major languages (English, Chinese and Malay). The questionnaire had information on demographics (gender, age and ethnicity), family eye history, preterm history, medical history and history of any ocular complaints. On the day of screening the consent forms and the questionnaires were collected. Children whose parents gave their written consent to participate in this study were included for the eye screening.

\section{Vision screening}

All preschool children underwent two basic screening procedures which included distant visual acuity test and depth perception test. Measurement of the distant visual acuity was performed using the Sheridan Gardiner Test Complete (Keeler, UK) and the Cardiff charts. Depth perception test or stereopsis assessment was performed using the Langs stereotest. These tests were performed by optometrists and trained staff nurses. The children were subjected to distant visual acuity test first followed by stereopsis assessment. Every child underwent a pretest before the actual assessment of the test procedure. The distant visual acuity test was measured monocularly at a distance of 6 meter. The right eye was tested first before the left eye. The test results of both the eyes were recorded separately. Stereopsis was measured binocularly and the results were recorded as "pass" if the child can identify the figures in the chart correctly and fail if the child was unable to locate the pictures. Children whose visual acuity was worse than $6 / 12$ in one or both the eyes and those who fail in the depth perception test were referred to the eye clinic for a detailed eye examination [7].

\section{Referral and further evaluation}

Children who needed eye referral were sent home with a letter to inform their parents about their condition and also a referral letter to the eye clinic for a comprehensive eye examination. Examinations in the eye clinic were performed by trained ophthalmologists. These include visual acuity assessment, cover-uncover and alternate cover tests, ocular movements, cycloplegic refraction, slit-lamp examination and dilated fundus examination. Significant refractive error were defined as hyperopia $\geq 3.00$ diopters (D), myopia $\geq 1.00 \mathrm{D}$ or astigmatism $\geq 1.50 \mathrm{D}$ in either eye, or anisometropia $\geq 2.00 \mathrm{D}$ [8]. Children with underlying refractive errors were prescribed glasses and children with other ocular problems were managed accordingly. Amblyopia was defined as visual acuity worse than 0.3 LogMAR (worse than 20/40) in the affected eye and/or a 2 LogMAR line difference between the two eyes and the presence of an amblyogenic factor [9].

\section{Statistical analysis}

Data entry, cleaning and analyses were performed using SPSS 17.0 for windows. Data analysis was carried out by PS Mallika. Descriptive statistical analysis was performed and results were reported. Categorical data analysis was performed by using either chi-square test or Fishers exact test as appropriate.

\section{Results}

\section{Demography}

All the schools inspected were able to provide a suitable environment for vision screening. Of the 450 preschool children who were eligible to participate in the study, $400(88.8 \%)$ were screened for eye diseases, $30(6.6 \%)$ were absent, and $20(4.4 \%)$ refused to participate. The 
Table 1 Demographic data

\begin{tabular}{lcc}
\hline Variables & $\boldsymbol{n}$ & $\%$ \\
\hline Gender & 196 & 49 \\
Male & 204 & 51 \\
Female & & \\
Age Group (Years) & 51 & 12.8 \\
4 & 163 & 40.8 \\
5 & 186 & 46.5 \\
6 & & \\
Race & 115 & 28.8 \\
Malay & 131 & 32.8 \\
Chinese & 60 & 15 \\
Iban & 76 & 19 \\
Bidayuh & 18 & 4.5 \\
Others & & \\
\hline
\end{tabular}

demographic profile of our study population is given in Table 1. Male: female ratio was almost 1:1. Majority of the children were in the 6 years old age group. Mean age was $5.33 \pm 0.69$ years. Ethnic composition in the different age groups is given in Table 2. About $80 \%$ of the children had visual acuity of $6 / 6$ in both the eyes (Table 3 ).

The prevalence of visual impairment in our population was $5 \%(95 \% \mathrm{CI}=3.3 \%, 7.6 \%)$. Ninety six percent of the children passed the distant vision screening test and $99 \%$ of them passed the stereopsis test. Of the 20 who did not pass the distant visual acuity test, one was found to have speech disorder; the others were due to eye problems. Visual impairment was common among boys $(n=13,65 \%)$ compared to girls $(n=7,35 \%)$. However, the difference is not statistically significant $(\mathrm{p}=0.142)$. Children in age group of 6 were found to have visual impairment more compared to other age groups (statistically not significant, $\mathrm{p}=0.732$ ) (Table 4). Children from the Bidayuh ethnic group had higher number of visual impairment $(n=8)$ compared other ethnic groups (statistically not significant, $\mathrm{p}=0.171$ ). A positive family history of eye disease was present in $24 \%$ of children and the most common was family history of refractive errors. History of medical illness was seen in $6 \%$ of children and prematurity in $6.8 \%$. Twenty eight percent of the children had
Table 3 Distribution of visual acuity in both eyes

\begin{tabular}{cccccc}
\hline & \multicolumn{2}{c}{ Right eye } & & \multicolumn{2}{c}{ Left eye } \\
\cline { 2 - 3 } \cline { 5 - 6 } Visual acuity & $\boldsymbol{n}$ & \% & & $\boldsymbol{n}$ & $\%$ \\
\hline $6 / 6$ & 335 & 83.75 & & 323 & 80.75 \\
$6 / 9$ & 48 & 12.00 & & 60 & 15.00 \\
$6 / 12$ & 12 & 3.00 & 10 & 2.50 \\
$6 / 18$ & 3 & 0.75 & 5 & 1.25 \\
$6 / 24$ & 1 & 0.25 & 1 & 0.25 \\
$6 / 36$ & 0 & 0.00 & 0 & 0.00 \\
$6 / 60$ & 1 & 0.25 & 0 & 0.00 \\
$<6 / 60$ & 0 & 0.00 & 1 & 0.25 \\
Total & 400 & 100 & 400 & 100 \\
\hline
\end{tabular}

ocular complaints and the commonest ocular complaint was photophobia.

\section{Refractive errors}

Refractive errors were the most prevalent cause of visual impairment (95\%, 95\% CI $=76.2,98.8$ ); astigmatism the commonest. Only one child had exotropia. Majority of the children were found to have compound myopic astigmatism $(63.2 \%, 95 \% \mathrm{CI}=40.8,80.9)$ (Table 5). Most of the children had refractive errors involving both eyes $(n=15)$. Of those who were found to have unilateral refractive error $(n=5)$, the left eye was more frequently affected then the right eye.

\section{Discussion}

The prevalence of visual impairment in our study was $5 \%(95 \% \mathrm{CI}=3.3 \%, 7.6 \%)$; mostly due to refractive errors. This figure is comparable with other populations. In the Baltimore Pediatric Eye Study, the percentage of preschool-aged children requiring spectacle correction was about $1.2 \%$ among White children and $1.8 \%$ among African-American children [3]. Jamali et al. reported that about $6.3 \%$ of the children entering school in Iran were at risk of amblyopia; mostly due to refractive errors [10]. In Hong Kong, about $4.4 \%$ of preschool children had either reduced visual acuity or strabismus [11]. Chia et al. reported a prevalence of $1.19 \%$ among Singaporean children aged 30 to 72 months [12]. While in Nepal, Karki reported that $5.97 \%$ of children aged 4 to 5 years have amblyopia [13].

Table 2 Ethnic composition in different age groups

\begin{tabular}{|c|c|c|c|c|c|c|c|c|c|c|c|c|}
\hline \multirow{3}{*}{ Age (years) } & \multicolumn{10}{|c|}{ Ethnicity } & \multicolumn{2}{|c|}{ Total } \\
\hline & \multicolumn{2}{|c|}{ Malay } & \multicolumn{2}{|c|}{ Chinese } & \multicolumn{2}{|c|}{ Iban } & \multicolumn{2}{|c|}{ Bidayuh } & \multicolumn{2}{|c|}{ Others } & \multirow[b]{2}{*}{$n$} & \multirow[b]{2}{*}{$\%$} \\
\hline & $n$ & $\%$ & $n$ & $\%$ & $n$ & $\%$ & $n$ & $\%$ & $n$ & $\%$ & & \\
\hline 4 & 4 & 1.0 & 33 & 8.25 & 8 & 2.0 & 3 & 0.75 & 3 & 0.75 & 51 & 12.75 \\
\hline 5 & 49 & 12.25 & 44 & 11.0 & 30 & 7.5 & 36 & 9.0 & 4 & 1.0 & 163 & 40.75 \\
\hline 6 & 62 & 15.5 & 54 & 13.5 & 22 & 5.5 & 37 & 9.25 & 11 & 2.75 & 186 & 46.5 \\
\hline Total & 115 & 28.75 & 131 & 32.75 & 60 & 15.0 & 76 & 19.0 & 18 & 4.5 & 400 & 100.0 \\
\hline
\end{tabular}


Table 4 Distribution of visual impairment and age group

\begin{tabular}{|c|c|c|c|c|c|c|c|}
\hline & & \multicolumn{4}{|c|}{ VA test } & \multicolumn{2}{|c|}{ Total } \\
\hline & & \multicolumn{2}{|c|}{ Fail* } & \multicolumn{2}{|c|}{ Pass } & \multirow[b]{2}{*}{$n$} & \multirow[b]{2}{*}{$\%$} \\
\hline & & $n$ & $\%$ & $n$ & $\%$ & & \\
\hline \multirow[t]{3}{*}{ Age } & 4 years & 2 & 3.92 & 49 & 96.08 & 51 & 100.0 \\
\hline & 5 years & 7 & 4.29 & 156 & 95.71 & 163 & 100.0 \\
\hline & 6 years & 11 & 5.91 & 175 & 94.09 & 186 & 100.0 \\
\hline Total & & 20 & 5.00 & 380 & 95.00 & 400 & 100.0 \\
\hline
\end{tabular}

The type of refractive error varies among different populations. Astigmatism was the commonest type of refractive error in our population. The axis of astigmatism in our study population was mostly with-the-rule. Significant refractive errors were uncommon. Hyperopia was found to be the most prevalent refractive error among preschool children in the Baltimore Pediatric Eye Study and in Iran $[10,14]$. In Singapore, where the prevalence of myopia is one of the highest in the world, preschool children had a high prevalence of myopia (11\%-15\%) $[15,16]$. The type of refractive errors in a population may change with time. Fan et al. found that in Hong Kong, the commonest type of refractive error shifted from astigmatism to myopia over a decade (1996-2007) [11].

Strabismus was found in one of the 20 children who did not pass the screening tests. The prevalent type of concomitant strabismus varies in different study population. Esotropia is more common in White population while exotropia in Asians [17]. In the Baltimore Pediatric Eye Study, the prevalence of strabismus was $0.3 \%$; most due to esotropia [14]. Chia et al. reported a $0.80 \%$ prevalence of strabismus among preschool Singaporean Chinese. The exotropia-esotropia was about 7:1 [12].

The rate of testability increases with age [18]. As our sample consisted of older preschool children (aged 4 to 6 years), all 400 children in our study were testable for distant visual acuity and stereopsis. This is comparable with the findings of other studies $[18,19]$. This finding will provide a basis for future research to the evaluation of the effectiveness of these (Sheridan Gardiner Test Complete (Keeler, UK) and Langs stereotest) screening tests to detect amblyopia in our population.

\section{Limitation}

The main limitation is due to the inherent weakness of a cross-sectional study. Data regarding the developmental milestone of the children were not collected. The presence of developmental delay may indicate the presence of associated visual impairment [20].

The non-respondent rate was about $11 \%$ and this may result in selection bias. The bias was influenced by caregiver characteristics where children who are already wearing spectacles may or may not be more prone to participate in

Table 5 Data of patients who had visual disorders

\begin{tabular}{|c|c|c|c|c|c|}
\hline Patient & Right eye & Refraction & Left eye & Refraction & Visual Impairment \\
\hline 1 & Compound myopic astigmatism & $-1.0 /-1.5 / 180$ & Compound myopic astigmatism & $-2.25 /-0.75 / 180$ & \\
\hline 2 & Compound myopic astigmatism & $-1.0 /-2.75 / 180$ & Compound myopic astigmatism & $-6.0 /-3.25 / 180$ & PRESENT \\
\hline 3 & Mixed astigmatism & $0.25 /-0.75 / 180$ & Mixed astigmatism & $0.25 /-0.5 / 180$ & \\
\hline 4 & Compound myopic astigmatism & $-1.5 /-2.0 / 180$ & Compound myopic astigmatism & $-1.5 /-2.5 / 180$ & \\
\hline 5 & Mixed astigmatism & $0.75 /-0.5 / 170$ & Mixed astigmatism & $1.0 /-1.25 / 180$ & \\
\hline 6 & Simple myopia & -0.5 & Simple myopia & -0.5 & \\
\hline 7 & Compound myopic astigmatism & $-1.5 /-0.5 / 019$ & Mixed astigmatism & $2.0 /-1.75 / 173$ & PRESENT \\
\hline 8 & Compound myopic astigmatism & $-2.75 /-0.25 / 152$ & Compound myopic astigmatism & $-2.25 /-0.25 / 146$ & \\
\hline 9 & Compound myopic astigmatism & $-3.0 /-0.25 / 180$ & Compound myopic astigmatism & $-2.75 /-0.25 / 180$ & \\
\hline 10 & Compound myopic astigmatism & $-3.0 /-1.5 / 030$ & Compound myopic astigmatism & $-1.25 /-1.5 / 160$ & \\
\hline 11 & Simple myopic astigmatism & $0 /-1.5 / 180$ & Simple myopic astigmatism & $0 / 1.5 / 180$ & \\
\hline 12 & Mixed astigmatism & $0.75 /-2.75 / 180$ & Mixed astigmatism & $0.75 /-2.25 / 180$ & \\
\hline 13 & Compound myopic astigmatism & $-2.5 / 0.75 / 180$ & Compound myopic astigmatism & $-2.25 / 0.5 / 180$ & \\
\hline 14 & Squint & PLANO & normal & PLANO & PRESENT \\
\hline 15 & Compound myopic astigmatism & $-3.0 /-0.5 / 180$ & Compound myopic astigmatism & $-2.5 / 0.5 / 180$ & \\
\hline 16 & normal & PLANO & Compound myopic astigmatism & $-2.25 /-0.25 / 179$ & \\
\hline 17 & normal & PLANO & Mixed astigmatism & $0.5 /-2.25 / 166$ & \\
\hline 18 & normal & PLANO & Compound myopic astigmatism & $-6.26 /-1.5 / 009$ & PRESENT \\
\hline 19 & normal & PLANO & Compound myopic astigmatism & $-1.5 /-0.5 / 163$ & \\
\hline 20 & Compound myopic astigmatism & $-5.0 /-1.0 / 180$ & Compound myopic astigmatism & $-1.5 / 1.0 / 180$ & PRESENT \\
\hline
\end{tabular}


the study. It is difficult to determine the direction of this bias. However, a higher respondent rate does not necessarily prevent selection bias [21].

The children were only tested for visual acuity and stereopsis. Comprehensive eye examinations were only offered to those who failed the screening tests. In other prevalence studies, all children were examined $[3,10,12,13,16]$. It is therefore difficult to compare our findings because of the statistics. Children with mild strabismus may not be detected as Hirschberg test and cover test was not performed on the field. Therefore strabismus is underreported in this study. Retesting was not performed in this cross-sectional study. Although pre-test was given prior to actual screening, the possibility of poor cooperation cannot be ruled out.

The study was conducted among the urban population in Kuching district. It is reasonable to assume that the findings should apply to major towns with similar socioeconomic class such as Miri, Sibu or Bintulu. Generalization of the findings to the rural population should be viewed with caution. The prevalence of decreased presenting visual acuity may be higher in rural communities where spectacles are less available.

\section{Conclusion}

The study is a small but important step in the effort to understand the problem of visual impairment among our preschool children. Our study showed that it is feasible to measure distant visual acuity and stereopsis in this age group. It provides some idea on the magnitude of the condition. However, the value of performing vision screening in preschool children is yet to be determined. Further research is needed in this aspect.

\section{Competing interests}

The authors declare that they have no competing interests.

\section{Authors' contributions}

MP is the principal investigator. Data analysis was carried out by MP. All authors were involved with the drafting of the manuscript. All authors read and approved the final manuscript.

\section{Acknowledgement}

Research and Innovation Management Centre (RIMC), UNIMAS.

\section{Funding}

This project was supported by the UNIMAS Small Grant Scheme. Project ID: SGS/01(S63)/761/2010(38).

\footnotetext{
Author details

'Department of Ophthalmology, Faculty of Medicine and Health Sciences, Universiti Malaysia Sarawak (UNIMAS), Lot 77, Seksyen 22, Kuching Town Land District, Jalan Tun Ahmad Zaidi Adruce, Kuching, Sarawak 93150, Malaysia. ${ }^{2}$ Department of Nursing, Faculty of Medicine and Health sciences, University Malaysia Sarawak (UNIMAS), Lot 77, Seksyen 22, Kuching Town Land District, Jalan Tun Ahmad Zaidi Adruce, Kuching, Sarawak 93150, Malaysia. ${ }^{3}$ Department of Ophthalmology, Sarawak General Hospital, Kuching, Sarawak 93150, Malaysia. ${ }^{4}$ Department of Family Medicine, Faculty of Medicine and Health Sciences, Universiti Malaysia Sarawak (UNIMAS), Lot 77, Seksyen 22, Kuching Town Land District, Jalan Tun Ahmad Zaidi Adruce, Kuching, Sarawak 93150, Malaysia.
}

Received: 30 November 2012 Accepted: 15 April 2013

Published: 19 April 2013

\section{References}

1. Prechtl HF, Cioni G, Einspieler C, Bos AF, Ferrari F: Role of vision on early motor development: lessons from the blind. Dev Med Child Neurol 2001, 43(3):198-201.

2. Hong $\mathrm{CL}$, Press $\mathrm{L}$ : Visual factors in childhood behavioral disorders. California Optometry 2009, 36(4):46-54.

3. Friedman DS, Repka MX, Katz J, Giordano L, lbironke J, Hawes P, Burkom D, Tielsch JM: Prevalence of decreased visual acuity among preschool-aged children in an American urban population: the Baltimore pediatric eye disease study, methods, and results. Ophthalmology 2008, 115(10):1786-1795.

4. American Academy of Pediatrics: Eye examination in infants, children, and young adults by pediatricians. Pediatrics 1996, 98:153.

5. Community Pediatric Committee: Vision screening in infants and children. Pediatr Child Health 1998, 3:361-362.

6. Population and Housing Census of Malaysia: Population distribution and basic demographic characteristics 2010. Malaysia: Department of Statistics; 2010:74.

7. Screening Procedure for Distance Visual Acuity: Grades K, 1, 2, 3, 5, 7 and 10, School Vision Screening Guidelines. Albany, New York: The University of the State of New York; 2011:7.

8. Ibironke JO, Friedman DS, Repka MX, Katz J, Giordano L, Hawse P, Tielsch $J \mathrm{M}$ : Child development and refractive errors in preschool children. Optom Vis Sci 2011, 88:181-187.

9. Ohlsson J: Defining amblyopia: the need for a joint classification. Strabismus 2005, 13:15-20.

10. Jamali P, Fotouhi A, Hashemi H, Younesian M, Jafari A: Refractive errors and amblyopia in children entering school: Shahrood, Iran. Optom Vis Sci 2009, 86(4):364-369.

11. Fan DS, Lai C, Lau HH, Cheung EY, Lam DS: Change in vision disorders among Hong Kong preschoolers in 10 years. Clin Experiment Ophthalmol 2011, 39(5):398-403.

12. Chia A, Dirani M, Chan YH, Gazzard G, Au Eong KG, Selvaraj P, Ling Y, Quah BL, Young TL, Mitchell P, Varma R, Wong TY, Saw SM: Prevalence of amblyopia and strabismus in young Singaporean Chinese children. IOVS 2010, 51:3411-3417.

13. Karki KJD: Prevalence of amblyopia in ametropias in a clinical set-up. Kathmandu Univ Med Jour 2006, 4(16):470-473.

14. Giordano L, Friedman DS, Repka MX, Katz J, Ibironke J, Hawes P, Tielsch JM: Prevalence of refractive error among preschool children in an urban population: the Baltimore pediatric eye disease study. Ophthalmology 2009, 116(4):739-746.

15. Dirani M, Chan YH, Gazzard G, Hornbeak DM, Leo SW, Selvaraj P, Zhuo B, Young TL, Mitchell P, Varma R, Wong TY, Saw SM: Prevalence of refractive error in Singaporean Chinese children: the strabismus, amblyopia, and refractive error in young Singaporean Children (STARS) study. Invest Ophthalmol Vis Sci 2010, 51(3):1348-1355.

16. Lim HC, Quah BL, Balakrishnan V, Lim CH, Tay V, Emmanuel SC: Vision screening of four-year old children in Singapore. Singapore Med J 2000, 41:271-278.

17. Engle EC: Genetic basis of congenital strabismus. Arch Ophthalmol 2007, 125:189-195.

18. Trager MJ, Dirani M, Fan Q, Gazzard G, Selvaraj P, Chia A, Wong TY, Young $T L$, Varma R, Saw SM: Testability of vision and refraction in preschoolers: the strabismus, amblyopia, and refractive error study in singaporean children. Am J Ophthalmol 2009, 148(2):235-241.

19. Pai AS, Rose KA, Samarawickrama C, Fotedar R, Burlutsky G, Varma R, Mitchell P: Testability of refraction, stereopsis, and other ocular measures in preschool children: the Sydney paediatric eye disease study. J AAPOS 2012, 16(2):185-192.

20. Warburg M: Visual impairment among people with developmental delay. J Intellec Disabil Res 1994, 38:423-432.

21. der Wiel AB, van Exel E, de Craen AJ, Gussekloo J, Lagaay AM, Knook DL, Westendorp RG: A high response is not essential to prevent selection bias: results from the Leiden 85-plus study. J Clin Epidemiol 2002, 55(11):1119-1125.

doi:10.1186/1471-2415-13-16

Cite this article as: Premsenthil et al:: The screening of visual impairment among preschool children in an urban population in Malaysia; the Kuching pediatric eye study: a cross sectional study. BMC Ophthalmology 2013 13:16. 